\title{
Ideas for Specific, Low-Power and Cost-Effective Chemical Sensors ${ }^{\dagger}$
}

\author{
Olga Casals ${ }^{1,2}$, Cristian Fàbrega ${ }^{1,2}$ and Joan Daniel Prades 1,2,* \\ 1 Departament d'Enginyeria Electrònica i Biomèdica, Universitat de Barcelona, 08028 Barcelona, Spain; \\ ocasals@el.ub.edu (O.C.); cfabrega@el.ub.edu (C.F.) \\ 2 Institute of Nanoscience and Nanotechnology (IN²UB), Universitat de Barcelona, 08028 Barcelona, Spain \\ * Correspondence: dprades@el.ub.edu; Tel.: +34-934-039-159 \\ † Presented at the Eurosensors 2018 Conference, Graz, Austria, 9-12 September 2018.
}

Published: 7 December 2018

Specificity, or the ability of detecting one single species in the presence of many others, is one of the most sought after features in chemical and gas sensors. However, attaining such a feature involves adding complexity to the detection system, normally at the expense of a higher power demand and ultimately, at a higher cost.

Our research of the last 10 years has been focused on the implementation of new approaches to improve specificity and lower power consumption at the same time. In this presentation we will review our main contributions in the context of the state-of-the-art.

First, we will show how power consumption in semiconductor devices can be lowered to just a few microwatts by means of the self-heating effect occurring in nanomaterials [1]. Only a decade ago, this principle was proved with fully hand-made devices [2]. Today, it is possible to achieve comparable efficiencies with devices produced in mass scale, using widely spread micro and nanofabrication techniques.

Second, we will move to light activated chemical sensors [3], where dramatic power savings can be achieved by combining the power efficiency of light emitting diodes (LED) with aggressive miniaturization efforts. Using industry standard technologies, it is possible to offer sub-milliwatt power demands in monolithic integrated microLED devices that can be produced in large amounts. We will also show how optical activation opens the door to complementary operation approaches, based on light energy harvesting that can enable virtually zeropower devices in the near future [4].

Third, we will show how the previous approaches can be combined with surface functionalization methods to achieve high specificity [5]. In combination, with color indicators, some of these gas-specific receptors provide direct path to inexpensive optical readout systems, based on sensors printed on plastic or paper and smartphone cameras [6]. This last approach enables massive sensing applications thanks to their potential for sub-1-eurocent cost per sensor.

\section{References}

1. Fàbrega, C.; Casals, O.; Hernández-Ramírez, F.; Prades, J.D. A review on efficient self-heating in nanowire sensors: Prospects for very-low power devices. Sens. Actuators B Chem. 2017, 256, 797-811, doi:10.1016/j.snb.2017.10.003.

2. Prades, J.D.; Jimenez-Diaz, R.; Hernandez-Ramirez, F.; Barth, S.; Cirera, A.; Romano-Rodriguez, A.; Mathur, S.; Morante, J.R. Ultralow power consumption gas sensors based on self-heated individual nanowires. Appl. Phys. Lett. 2008, 93, 123110, doi:10.1063/1.2988265.

3. Prades, J.D.; Jimenez-Diaz, R.; Manzanares, M.; Hernandez-Ramirez, F.; Cirera, A.; Romano-Rodriguez, A.; Mathur, S.; Morante, J.R. A model for the response towards oxidizing gases of photoactivated sensors based on individual $\mathrm{SnO}_{2}$ nanowires. Phys. Chem. Chem. Phys. 2009, 11, 10881-10889, doi:10.1039/b915646a. 
4. Hoffmann, M.W.G.; Gad, A.E.; Prades, J.D.; Hernandez-Ramirez, F.; Fiz, R.; Shen, H.; Mathur, S. Solar diode sensor: Sensing mechanism and applications. Nano Energy 2013, 2, 514-522.

5. Hoffmann, M.W.G.; Mayrhofer, L.; Casals, O.; Caccamo, L.; Hernandez-Ramirez, F.; Lilienkamp, G.; Daum, W.; Moseler, M.; Waag, A.; Shen, H.; et al. A Highly Selective and Self-Powered Gas Sensor Via Organic Surface Functionalization of p-Si/n-ZnO Diodes. Adv. Mater. 2014, 26, 8017-8022, doi:10.1002/adma.201403073.

6. Fabrega, C.; Fernández, L.; Monereo, O.; Pons-Balagué, A.; Xuriguera, E.; Casals, O.; Waag, A.; Prades, J.D. Highly Specific and Wide Range $\mathrm{NO}_{2}$ sensor with color readout. ACS Sens. 2017, doi:10.1021/acssensors. $7 \mathrm{~b} 00463$.

(C) 2018 by the authors. Licensee MDPI, Basel, Switzerland. This article is an open access article distributed under the terms and conditions of the Creative Commons Attribution (CC BY) license (http://creativecommons.org/licenses/by/4.0/). 